\title{
Prashant Mali
}

\author{
RNA-editing tools from a cricket-playing electrical engineer turned bioengineer.
}

G etting ideas "has always been an active, ATP-consuming process" for him, says Prashant Mali, a bioengineer at the University of California in San Diego. When a problem intrigues him, an idea takes shape only after he has thought long and hard about it. He has been pondering how prevalent CRISPR-based gene-editing tools have become. Because the methods involve prokaryotic proteins, CRISPR risks immunogenic reactions for applications in people. Mali sought a way to harness endogenous proteins and tapped into an approach described over two decades ago: RNA editing. It's how cells change a base in single-stranded RNA post-transcriptionally. Engineering and optimization steps led Mali and his team to two tools for making targeted RNA edits. Both tools entail the recruitment of enzymes from the ADAR family, which stands for 'adenosine deaminase acting on RNA'. When an ADAR enzyme deaminates adenosine, it becomes inosine, which looks similar to guanine, and the nucleotide can then pair with cytosine. RNA editing involves an ADAR guide RNA (adRNA), a short RNA sequence with a region complementary to the target that recruits ADARs and guides the RNA-editing process.

One of Mali's tools is GluR2 adRNA, which has an RNA component and a fully human protein component, is engineered from the cells' own GluR2 pre-mRNA and can potentially be part of a fully human RNA-editing system for therapeutic purposes, says Mali. The other tool is the synthetic MS2 adRNA that could be used for targeted screens such as when a lab introduces point mutations to see their impact on protein function.

"The nice thing about RNA is that, unlike DNA, RNA is single-stranded largely and it is accessible," he says. Editing RNA is of interest, for example, when a lab wishes to modify a protein a gene makes but not alter the underlying gene.

Mali and his team looked at off-target effects. "The enzymes themselves, being RNA-binding proteins, can bind around in the transcriptome promiscuously and that can increase off-targets," he says. Off-targets

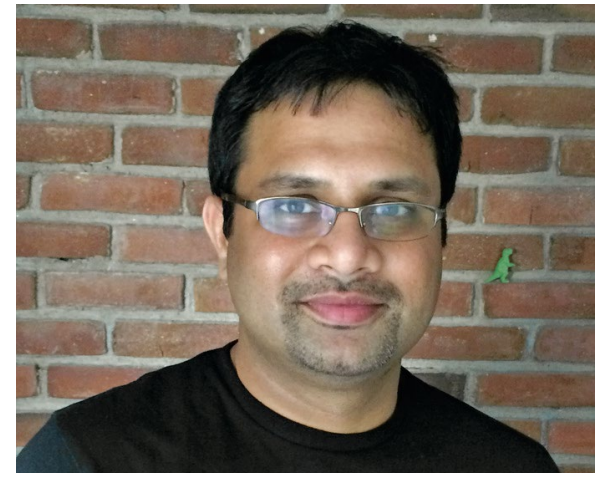

Prashant Mali

are mainly driven by enzyme overexpression. Some of his developed designs can avoid that because of the way they "recruit" endogenous ADARs. ADAR1 is expressed in almost all cells in the human body. In some tissues, such as brain and lung, both ADAR1 and ADAR2 are expressed.

Mali says he and his team are glad about the efficiencies and yields and the tool optimization for in vivo work in mice. Looking ahead he wants to engineer different adRNA designs to advance ways of recruiting endogenous ADARs. Another aspect on his to-do list: making the adRNAs inducible with, for example, small molecules. That would make them "tunable on demand," he says. One could shut off adverse reactions by, for instance, withdrawing the corresponding small molecule. "I've always felt that RNA editing is just a special place to be, because you have this aspect of tunability and reversibility that you don't have with DNA targeting," says Mali. It's the tunability that makes these tools attractive also for therapeutic applications. "My core passion or at least my dream is that I can take something to the clinic and have an impact there," he says. "Of course it's something that is still far away, but I definitely want to give it my best shot."

Mali completed his $\mathrm{PhD}$ research in biomedical engineering at Johns Hopkins University and was a postdoctoral fellow in George Church's lab at Harvard Medical
School. He arrived at his $\mathrm{PhD}$ program as an electrical engineer and learned biology by completing the first year of medical school. "It was a most transformative event for me," he says. "I got sucked right into exploring biology and never did look back." A short rotation in the Hopkins lab of Peter Searson turned into an almost two-year-long stay focused on electrochemistry and physics. Mali has a "very unique ability to identify a problem and then go into the lab and solve it," says Searson. "Because he is so efficient in solving problems, he also has tremendous bandwidth, which makes it hard to keep up with his progress." Linzhao Cheng, Mali's $\mathrm{PhD}$ advisor at Hopkins, says "he is not afraid to try new things, and quite often he managed to succeed before many others who follow conventional wisdom."

\section{"I got sucked right into exploring biology and never did look back."}

Mali had been primed for biology. As an undergraduate in his native India he had worked in a solid-state physics lab, where his advisor coaxed him to apply engineering concepts to biology, such as for sensing molecules. This path is now coming full circle as Mali toys with building RNA nanotechnology that is switchable and programmable. "I feel like maybe we can do the same with the adRNAs as well," he says. "But that's purely a pipe dream right now." When he is not in the lab, he enjoys cricket. "Although I was always a better spectator than a player of the sport," he says. He has less time for cricket these days: his fouryear-old son keeps him running, "so the past few years have been a blur."

\section{Vivien Marx}

Published online: 27 February 2019

https://doi.org/10.1038/s41592-019-0332-z

\section{Reference}

Katrekar, D. et al. In vivo RNA editing of point mutations via RNA-guided adenosine deaminases. Nat. Methods. https://doi.org/10.1038/s41592-0190323-0 (2019). 